\title{
Tumor del saco endolinfático: imágenes de un caso
}

\section{Endolymphatic sac tumor: imaging case}

\author{
Valeria Sepúlveda C. ${ }^{1}$, Sebastián Bravo-Grau², \\ Sofia Waissbluth A. ${ }^{3}$
}

\section{Palabras clave}

Saco endolinfático, tumor, neoplasias, otorrinolaringología, radiología.

\author{
Keywords \\ Endolymphatic sac, tumor, neoplasms, otolaryngology, radiology.
}

\author{
'Escuela de Medicina, Pontificia \\ Universidad Católica de Chile. Santiago, \\ Chile. \\ 2Departamento de Radiología, Unidad de \\ Neurorradiología, Pontificia Universidad \\ Católica de Chile. Santiago, Chile. \\ ${ }^{3}$ Departamento de Otorrinolaringología, \\ Pontificia Universidad Católica de Chile. \\ Santiago, Chile. \\ Los autores declaran no tener conflictos \\ de interés. \\ Recibido el 9 de agosto de 2020. \\ Aceptado el 9 de septiembre de 2020. \\ Correspondencia: \\ Sofia Waissbluth A \\ Departamento de Otorrinolaringología. \\ Pontificia Universidad Católica de Chile. \\ Marcoleta 352. Santiago, Chile. \\ Email: sofia.waissbluth@gmail.com
}

\section{Introducción}

El tumor del saco endolinfático (TSEL), o tumor de Heffner, es un tumor neuroectodérmico infrecuente del aspecto dorsal de la parte petrosa del hueso temporal, de tipo adenocarcinoma de bajo grado de origen del saco endolinfático. Tiene un bajo potencial maligno y es un tumor localmente agresivo del oído interno ${ }^{1}$, pero no se han reportado casos de metástasis a distancia ${ }^{2}$. Las lesiones pueden involucrar a células mastoideas, segmento mastoideo del nervio facial, canales semicirculares, cóclea, tímpano, foramen yugular, canal auditivo interno o el ápex petroso ${ }^{3}$.

Su incidencia en la población adulta es de aproximadamente $1: 30.000^{1}$, es más frecuente en la cuarta década de vida y en mujeres ${ }^{4}$. Estos tumores son extremadamente raros, con aproximadamente 200 casos reportados en la literatura desde su primera caracterización a fines de la década de $1980^{1,4}$. Se ha descrito un intervalo promedio de 84,7 meses entre el inicio de los síntomas y el diagnóstico ${ }^{3}$. Los síntomas más frecuentes son la hipoacusia neurosensorial progresiva (95\%), tinnitus (92\%), vértigo e inestabilidad (62\%), ataxia y síndrome vermiano o hemicerebeloso, o compromiso de los pares craneanos V, VII y VIII ${ }^{1-4}$. En su progresión clínica, se puede presentar presión intracraneana elevada o cefalea, vómitos y dilatación pupilar ${ }^{4}$. La compresión del cuarto ventrículo puede llevar a una hidrocefalia ${ }^{4}$.

Este tumor puede estar asociado a la enfermedad de Von Hippel-Lindau (VHL), con una prevalencia de hasta $24 \%^{1,2}$. Además, los pacientes con VHL tienen mayor riesgo de TSEL bilateral, hasta 1 por cada 3 casos $^{2}$. La enfermedad de VHL es una patología autosómica dominante de expresión variable, causada por una inactivación del gen VHL supresor de tumores, el que se ha mapeado en el brazo corto del cromosoma $3^{1,2}$. Esta mutación predispone a los pacientes a múltiples hemangioblastomas del sistema nervioso central, y a tumores y quistes de varios órganos, tales como, carcinoma renal de células claras, feocromocitoma y cistoadenoma seroso pancreático ${ }^{2}$.

Los hallazgos imagenológicos descritos en tomografía computada incluyen tumores de alta densidad, espiculados, punteados o reticulados ${ }^{3}$. En la resonancia magnética de cerebro, se encuentran áreas difusas de señal con intensidad aumentada en la secuencia T1 de imagen sin contraste, se relacionarían a la presencia de hemorragia, hendiduras de colesterol y material proteico en grandes tumores; en la secuencia T2, el tumor es hiperintenso heterogéneamente; y la secuencia gradiente podría mostrar áreas de susceptibilidad de 
gradiente alterado secundario a focos de hemorragia ${ }^{4,5}$.

El tratamiento indicado es principalmente quirúrgico. Dependiendo del tamaño y extensión del tumor, el abordaje puede ir desde una laberintectomía transmastoidea hasta una resección subtotal de la mastoides. Se puede igualmente considerar una embolización

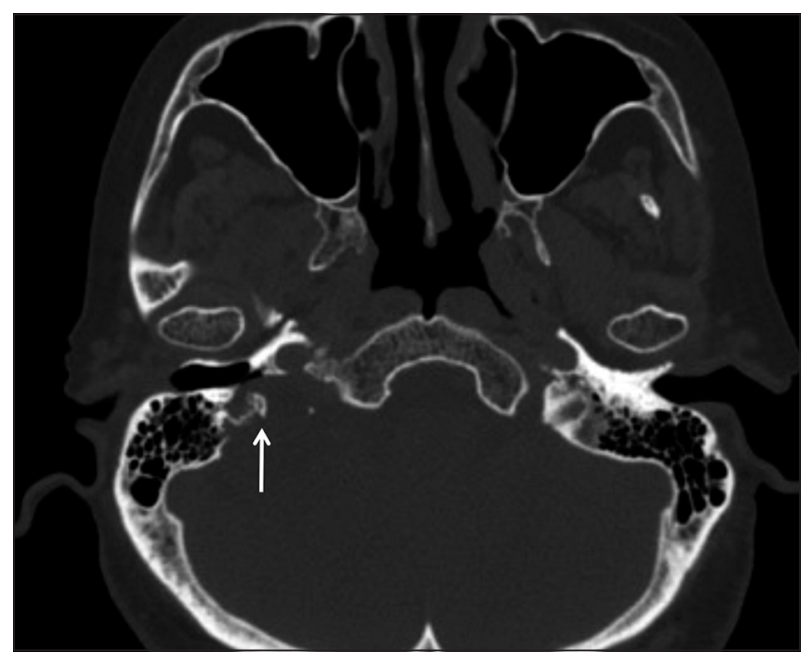

Figura 1. Tomografía computada de cerebro, corte axial, algoritmo de reconstrucción óseo. El tumor determina destrucción y remodelación ósea con una espiculación ósea intratumoral (flecha blanca). preoperatoria. El uso de la radioterapia no está claramente definido ${ }^{2}$. Los diagnósticos diferenciales a considerar son paraganglioma, meningioma, neurinoma, carcinoma del oído medio y papilomas del plexo coroideo ${ }^{3}$.

\section{Caso Clínico}

A continuación se presentan las imágenes de una paciente de sexo femenino de 66 años con diagnóstico de tumor del saco endolinfático derecho de 25 años de evolución. Inicialmente, presentó un cuadro de inestabilidad, crisis de vértigo recurrentes de aproximadamente una hora de duración y una hipoacusia súbita del oído derecho. Luego presenta tinnitus constante no pulsátil del oído derecho. No refiere cuadros de vértigo durante años, pero en el último año, ha evolucionado con mayor deterioro auditivo llegando a una hipoacusia profunda derecha. Se han realizado múltiples exámenes imagenológicos durante los años para observar la lesión. En la tomografía computada de cerebro (Figura 1), se puede apreciar una lesión expansiva petrosa derecha con remodelación ósea. En la última resonancia magnética cerebral (Figuras 2 y 3 ),

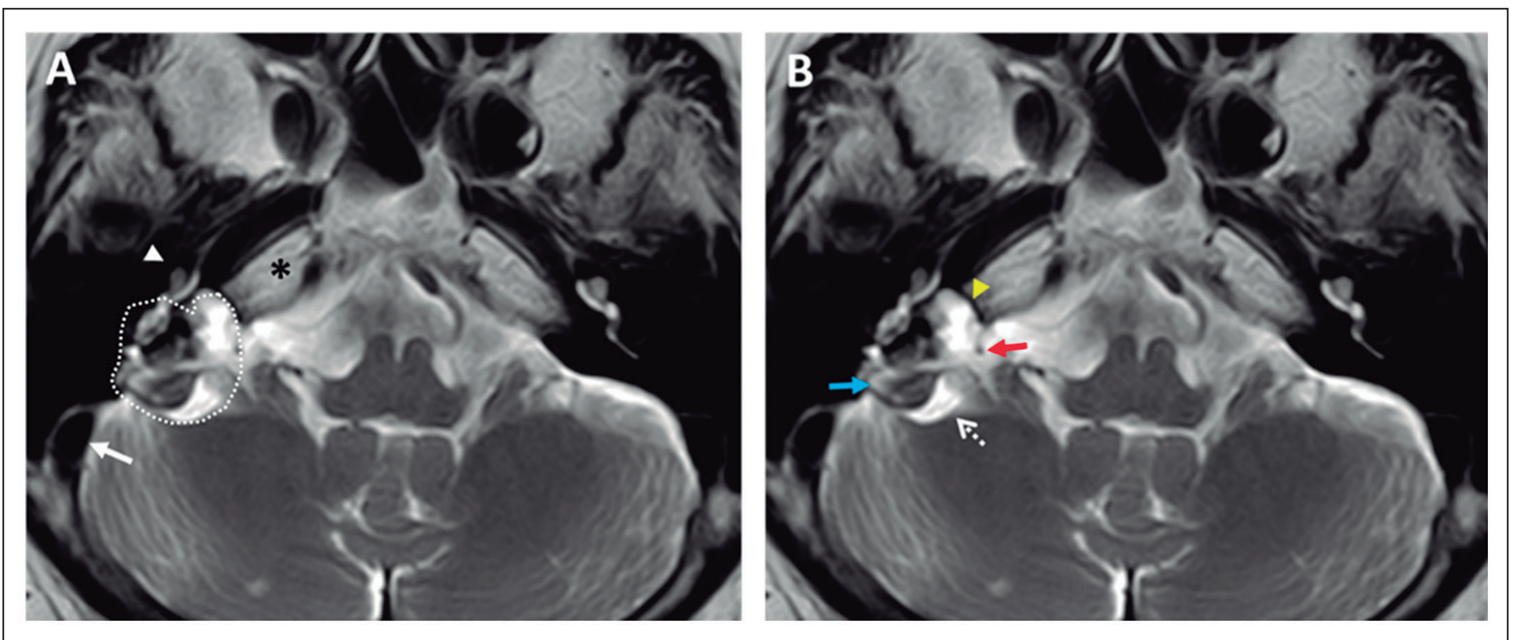

Figura 2. Resonancia magnética de cerebro, T2SE axial. A. Delimitación de la lesión lobulada compatible con un tumor del saco endolinfático. Estructuras anatómicas adyacentes: cóclea (cabeza de flecha blanca), seno sigmoideo derecho (flecha blanca) y ápex petroso del hueso temporal derecho $\left(^{*}\right)$. B. Lesión lobulada de señal heterogénea con componente hiperintenso en T2 y niveles líquido-líquido (por hemorragia intratumoral) (flecha celeste). Su componente anteromedial determina remodelación y destrucción ósea del segmento petroso del temporal, con compromiso del conducto auditivo interno (cabeza de flecha amarillo). Hacia medial ocupa la cisterna bulbocerebelosa y pontocerebelosa inferior derechas (flecha roja). El componente posterolateral determina efecto de masa sobre el cerebelo (flecha blanca punteada). 
se observa una masa lobulada con extensión al bulbo yugular (Figura 3) y al conducto auditivo interno, con efecto de masa de la cisterna pontocerebelosa y el cerebelo (Figura 2B). El tumor se ha mantenido de tamaño similar durante años, sin mayores cambios, por lo cual no se ha realizado un tratamiento quirúrgico. Permanece en control clínico con resonancias seriadas.

\section{Bibliografía}

1. Bellairs JA, Gluth MB. A histopathological connection between a fatal endolymphatic sac tumour and von Hippel-Lindau disease from 1960. J Laryngol Otol. 2018;132(1):75-78. doi: 10.1017/S0022215117001888.

2. Zanoletti E, Girasoli L, Borsetto D, Opocher G, Mazzoni A, Martini A. Endolymphatic sac tumour in von Hippel-Lindau disease: management strategies. Acta Otorhinolaryngol Ital. 2017;37(5):423-429. doi: 10.14639/0392-100X-1402.

3. Le H, Zhang $\mathrm{H}$, Tao W, et al. Clinicoradiologic characteristics of endolymphatic sac tumors. Eur Arch Otorhinolaryngol. 2019; 276:2705-2714. doi: 10.1007/ s00405-019-05511-8.

4. Alkhotani A, Butt B, Khalid M, Binmahfoodh M, Al-Said Y. Endolymphatic sac tumor at the cerebellopontine angle: A case report and review of literature. Int J Surg. 2019;58:162-166. doi: 10.1016/j. ijscr.2019.04.032.

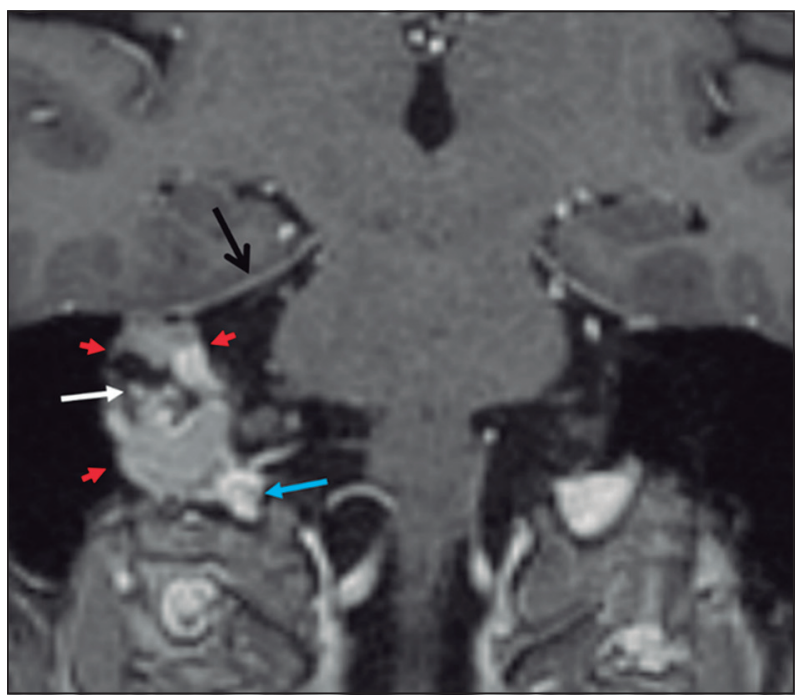

Figura 3. Resonancia magnética de cerebro, T1 (3D) con contraste, reconstrucción coronal. Muestra la lesión con componente espontáneamente hiperintenso en T1, con refuerzo heterogéneo con contraste en este caso en región central (flecha blanca). Tiene compromiso del foramen yugular derecho, contacta el segmento más distal del seno sigmoideo derecho y bulbo yugular (flecha azul), los que se encontraban permeables. Cabezas de flecha delimitan la lesión. Tentorio (flecha negra).

5. Patel NP, Wiggins RH, Shelton C. The radiological diagnosis of endolymphatic sac tumor. Laryngoscope. 2006;116(1):40-46. doi: 10.1097/01. mlg.0000185600.18456.36. 